\title{
A Cross-Cultural Comparison of Study Skills and Learning Strategies Between Saudi and American Students
}

\author{
Nasser Alasmari ${ }^{1}$, Zeineb Amri $^{1}$ \\ ${ }^{1}$ Department of English \& Translation, University of Jeddah, Jeddah, Saudi Arabia \\ Correspondence: Nasser Alasmari, Department of English \& Translation, University of Jeddah, Jeddah, Saudi Arabia. \\ E-mail: nsalasmari@uj.edu.sa
}

Received: December 20, 2019

Accepted: February 1, $2020 \quad$ Online Published: February 11, 2020

doi:10.5430/elr.v9n1p8

URL: https://doi.org/10.5430/elr.v9n1p8

\begin{abstract}
Study skills and learning strategies are essential in organizing and facilitating learning for academic purposes. Meanwhile, differences in the use of these skills among students coming from distinct cultures are usually based on stereotypes and prejudices.

This paper examined the study skills and learning strategies of 236 university students coming from two universities in Saudi Arabia and in the USA by means of the Study and Learning Strategies Inventory (LASSI), a follow up interview and a study diary. To investigate differences in study skills and learning strategies' use among university students, origin, as Saudi or American, was taken as the independent variable in this study. Results revealed that American students employ study skills and learning strategies other than those used by Saudi students when it comes to the cognitive skills. However, as far as the affective skills are concerned, both groups had difficulties. Such a finding suggests the possibility that study skills' use varies across cultures. The results of this study could be implemented, first, in raising the awareness of students, teachers, policy makers and counselors about the role of culture in study skills and learning strategies' use and second in offering training and counseling for incoming foreign university students.
\end{abstract}

Keywords: study skills, learning strategies, cross-cultural research, overseas universities

\section{Introduction}

The current information and technology era has resulted in a tremendous increase in knowledge. This new state of affairs has presented new challenges to the educational institution, the formal place that is considered as the setting of learning where students are supposed to become responsible for their own learning and be able to carry on learning once their academic life is over. In fact, the shift in focus from the instructional to the communicative method of learning has made the learner the center of the whole educational process; everything is to, from and about him/her. This focus brought about questions on how these learners' process information and the different techniques and strategies they use in order to understand, learn or remember the information provided for them. The case is more complicated at the tertiary level which entails hard work, perseverance and adjustments as the students are facing various challenges arising from the complexity and diversity of the different subjects studied during a limited span of time and dealt with in a stressful atmosphere characterized by deadlines, projects and examinations. Consequently, the student should cope with the scientific, psychological and social difficulties set by the nature of studying at the university. One suggested way to overcome these difficulties is to focus on the process of learning and help learners become aware of and develop the necessary learning strategies and study skills they need in order to easily gain and maintain knowledge and eventually pass the exams. Added to this are the concerns of educationalists, academicians and even students and parents who keep wondering on what makes the learning of a certain subject a success. Hard work is one way to achieve better performances. Some authors believed that it is a question of IQ that is related to genetics while others asserted that even though the aforementioned factors are important, the role of the students is much more highlighted in the act of studying. They argued that studying, itself, is a skill that students need to learn and develop in order to make a successful learning experience. 


\section{Literature Review}

\section{Learning Strategies and Study Skills}

Scarcella and Oxford (1992) referred learning strategies as "specifications, behaviors, steps or techniques- such as seeking out conversation partners, or giving oneself encouragement to tackle a difficult task- used by students to enhance their own learning" (p.63). These strategies are intentionally chosen by the learners themselves according to their own preferences and styles. As such, they become "useful tools for active, conscious, and purposeful self-regulation of learning" (p.2). They are grouped into six categories namely; cognitive, metacognitive, memory-related, compensatory, affective, and social.

Study skills, on the other hand, are defined as "competence in acquiring, recording, organizing, synthesizing, remembering and using information and ideas" (Proctor, Adams. Hurst. Prevatt. and Petscher, 2006, p.1). They encompass the mental processes students use to (1) understand new information and ideas found in lectures and textbooks, (2) make sense of and remember the new material, and (3) share this material with others in discussions, in writing course papers and research reports and in examinations. Related to these cognitive skills are skills such as managing one's time, selecting the proper time and place for study, and overcoming distractions. Underlying both skills are the attitudes students have towards studying mainly about their ability to study and their expectations.

\section{The Academic Attributes of Learning Strategies and Study Skills}

Many authors enlarged on the attributes of the study skills and learning strategies and foregrounded their contributions to the students' achievements of better academic results. Oxford (1990), for instance, described the learning strategies that language learners use as important tools that help them become more involved and responsible for their own learning and thus develop skills that enable them to keep learning even outside the classroom boundaries, which is, in itself, an objective educators have always attempted to realize. Some authors went further to suggest training the students to use the study skills and learning strategies and embed them in regular classroom activities in order to help them better control their learning and gain higher academic attainment. Earlier in the 1980s, having as objective to equip the students with the suitable study skills they need to succeed in their learning, the Louisiana State Board of Elementary and Secondary Education (BESE) initiated a move called "The Dynamics of Effective Study". Such skills include time management which refers to the skill of completing assigned tasks on time. The students who master the skill know how to schedule assigned tasks and organize or manage their time appropriately (Mutsotso and Abenga, 2010). The initiative also covered the motivation variable which refers to the students' willingness to learn a certain subject. As Haynes (1993) believed, learners with higher expectations to succeed and pass exams develop skills that help them learn. Steele (2010) added that study skills are abilities that reflect the intentional employment of the process of learning so as to achieve effective better learning outcomes especially at the university education.

Similarly, Pressley and Associates (1990) asserted the strong association between the students' employment of the learning strategies and the significant learning results they achieve in many subjects such as physics, reading, social studies and science. The same idea was conveyed by Vermunt (2007) who related success in academic life to the use of effective study skills. He added that effective studying leads to learning.

In order to illustrate the paramount role study skills play in the learners' life, Cottrell (2001) proposed that the development of study skills is not an end in itself but "part of a broader process of personal, academic and professional development" (p.46).

Consequently, acquiring study skills and learning strategies emerges as an essential component in a successful academic experience. As a matter of fact, the role study skills play in enhancing learning has led different university departments to include study skills courses within their curriculum and to design special programs to assist underprepared students as well as to the publication of a myriad of books and websites offering the best tips for the student to succeed. Furthermore, it has been repeatedly proved that study skills are positively related to academic success (Albaili, 1997; Al-Hillawani and Sartawi, 1997; and Proctor et al., 2006).

Vermunt (1998) carried out a research study where the sample was a group of university students from Germany. The author found out that the students' use of a particular study skill was determined by their attitudes towards learning itself and by their objectives behind studying. The same holds true with Alrabai (2018) who reviewed the literature that investigated in- country learning/ learner of English as a foreign language in Saudi Arabia with a particular focus on the common aspects that shape the Saudi students approaches to learning. He came to the conclusion that the Saudi learners' low achievement level in EFL is attributed to their demotivation to learn English as they demonstrate no desire to learn the language. To quote him, "Lack of motivation for learning English is widely recognized as a key 
characteristic of Saudi EFL learners that negatively affects both their EFL learning and the ensuing of EFL competence" (p.108).

\section{Cultural Variations among Overseas Students}

In another vein, proceeding with the fact that the world is now a "very small village", students' mobility especially at higher levels of education i.e. universities has grown very rapidly. Indeed, more and more students are moving abroad to do part of their studies either in neighboring countries or even in far-away establishments in totally different continents. Furthermore, the enormous geographic distances between nations and cultures have contracted thanks to technology, which has opened up new ways for the establishment of international relationships and interactions. This makes the understanding of cultural variations indispensable so as to establish new cross- border relationships and sustain old ones. Institutions at the tertiary level are the primary party to have played and still to play in such a situation through the internationalization of the classroom and university. Lee (2008) asserted that the registration of international students, in the United States and across the world, continued to increase.

As such, educators have started to shed light on the influence of cultural backgrounds on the students' academic achievements in settings that are relatively strange to them and focused on the different factors and variables that may play a role in helping them achieve their already set goals. In this vein, some authors argued that the study skills and learning strategies that these students develop are culturally related and therefore a strong emphasis should be placed on such variables. Kember and Gow (1990), for example, argued that cultural differences between countries result in the students' development and use of different patterns of learning and study skills.

Cross-cultural research studies are carried out in order to acknowledge and then consider the importance of knowing about the different cultural aspects, attitudes, and study habits the students have when they get access to local or overseas universities which would add to the literature about the learning strategies of the sample of the informants in this study. As a matter of fact, having a deeper understanding of the potential cultural differences between students from different origins and their associations with the study patterns they adopt, as claimed by Marambe, Vermunt, and Boshuizen (2012), would be highly informative about the different actions and measures that educationalists can take in order to help these students easily integrate to the new learning environment namely universities. Within similar lines of thought, Hofstede (2001) confirmed that culture, education and learning are three strongly interrelated variables.

However, cross-cultural comparisons of study skills have been made in relatively few studies (Vesta and Moreno, 1991). Tan and Goh (1999) believed that the cultural diversity impact on study skills is based on stereotypes and prejudices and lacks evidence and scientific rigor.

\section{The Objectives of the Study}

This paper aims to shed more light on the process of learning in an attempt to improve its quality. The focus on the association between cultural backgrounds and the different study skills and strategies used by students aims to help those who intend to complete their university studies abroad by providing them with an overview of the different cultural considerations to be taken in order not to hamper the learning process.

In this respect, the objective of this cross-cultural investigation is to identify the study skills and strategies that may be 'consistent' and specific to a certain cultural group or general to a group of cultures (Vesta and Moreno, 1991). The comparison of study skills presence and use among students from different cultures would be useful in both establishing a relationship between culture and study skills' use and also in developing special intervention programs for international students at local universities.

To fill in the gap of research in cross-cultural comparison of study skills use, this study tries to identify the presence of any similar and/or different patterns of studying among Saudi and American students, to find out the most effective study skills used by each of these parties and to make few suggestions that would help improve the development of such skills. It aims to find answers to the following questions:

1. What are the different study skills and learning strategies used by Saudi and American students?

2. Which study skills and learning strategies are similar/different used by Saudi and American students?

3. What are the most effective study skills and learning strategies used by Saudi and American learners? 


\section{Methodology}

\section{Participants}

The participants informing in this study were 236 students enrolled at two different universities: 156 students from the University of Jeddah, Saudi Arabia and 80 students from the University of Scranton in Pennsylvania, USA. Their selection was based on convenience, only those who were available during the time of data collection answered the questionnaire. In the selection process, the main variable taken into consideration is the participant's origin as Saudi or American.

\section{Instruments}

Three research instruments were used in this study: a questionnaire, a follow up interview and a diary sheet.

\section{The Questionnaire}

The questionnaire used for the purpose of this study is the Learning and Study Strategies Inventory (LASSI) designed by Weinstein and Palmer (1987). The LASSI focuses "on both covert and overt thoughts, behaviors, attitudes, motivations and beliefs that relate to successful learning in post-secondary educational and training settings" (Weinstein and Palmer, 2002, p.4). The LASSI consists of 80 items which are distributed among 10 scales. The ten scales investigated assess two different processes: one affective dealing with issues of motivation and self-management and the other cognitive focusing on information processing and self-testing abilities.

The affective scale includes (1) the Motivation scale (MOT) which is concerned with diligence, self-discipline and willingness to work hard; (2) the Attitude scale (ATT) assesses students' attitudes and interests in college; (3) the Anxiety scale (ANX) deals with the degree to which students worry about academic performance; (4) the Time-management scale (TMT) looks at the students' use of time management strategies for academic tasks, and finally (5) the Concentration (CON) scale investigates students' abilities to direct and maintain their attention on academic tasks. The cognitive scales, on the other hand, cover (6) the Information Processing (INP) scale which assesses the students' use of imagery, verbal elaboration, organization strategies and reasoning skills as learning strategies to help learn new information and skills, (7) The Selecting Main Idea Scale (SMI) evaluates the students' skill in identifying important information for study from less important details. The eighth scale is the Self-testing scale (SFT) (8) which focuses at the students' use of reviewing and comprehension monitoring techniques to determine their level of understanding of the information or task to be learned. The Test Strategies scale (TST) (9) assesses the students' use of both test preparation and testing taking strategies. The last scale is the Study Aids scale (STA) (10) which investigates the students' use of support techniques and materials to learn and remember new information. Table 1 gives two samples of items taken from each of the ten scales of the LASSI. 
Table 1. Sample items from the LASSI scales

\begin{tabular}{|c|c|}
\hline Scale & Sample item \\
\hline 1- Attitude & $\begin{array}{l}\text { I am able to study subjects I do not find interesting } \\
\text { I would rather not be at school. }\end{array}$ \\
\hline 2- Motivation & $\begin{array}{l}\text { I set high standards for myself in school. } \\
\text { Even when I do not like a course, I work hard to get a good grade. }\end{array}$ \\
\hline 3-Time- management & I put off studying more than I should. \\
\hline 4- Anxiety & $\begin{array}{l}\text { When it comes to studying, procrastination is a problem for me. } \\
\text { I am discouraged because of low grades. }\end{array}$ \\
\hline 5- Concentration & $\begin{array}{l}\text { Even when I am well prepared for a test, I feel very anxious. } \\
\text { I am very easily distracted from my studies. }\end{array}$ \\
\hline 6-Information-processing & $\begin{array}{l}\text { I find it hard to pay attention during lectures. } \\
\text { I try to relate what I am studying to my own experience. }\end{array}$ \\
\hline 7-Selecting Main Idea & $\begin{array}{l}\text { I translate what I am studying to my own words. } \\
\text { I have difficulty identifying the important points in my reading. }\end{array}$ \\
\hline 8-Study Aids & $\begin{array}{l}\text { When I listen to lectures, I am able to pick out important details. } \\
\text { If I am having trouble studying, I ask a classmate or the instructor. }\end{array}$ \\
\hline 9-Self-testing & $\begin{array}{l}\text { I try to find a study partner or study group for each of my classes. } \\
\text { I try to find potential test questions when reviewing my materials. }\end{array}$ \\
\hline 10-Test Strategies & $\begin{array}{l}\text { I review my notes before the next class. } \\
\text { I have difficulty adapting my studying to different types of courses. } \\
\text { When I take a test, I realize I have studied the wrong material. }\end{array}$ \\
\hline
\end{tabular}

The Structured Interview

The questionnaire administration was followed by a structured face-to-face interview. Items were developed to further explore the same ten scales of the LASSI in addition to including other open-ended questions to elicit more information about the students' attitudes and perceptions of studying. A total of 18 participants were interviewed.

Diary Sheets

Diaries have been used in this study to describe the daily practice of studying. Because of its personal aspect, diaries were not possible to carry out on a wide scope, the researcher asked the interviewed American students to keep a 'study diary' where they would reflect on the way they were studying. As for the Saudi students, no diaries were collected because of approaching period of the final exams.

\section{Data Analysis}

Both qualitative and quantitative analyses were applied on the different data obtained through the research instruments: the LASSI, the interview and the diary. Quantitative analysis was based on mainly the Statistical Package for Social Sciences (SPSS) 10.0 for Windows to analyze scores of respondents on the LASSI.

\section{Quantitative analysis}

Two nonparametric tests, available in the SPSS software, were used to analyze the significance of the relationship between the respondents' scores on the LASSI and their cultural origin. The choice of non-parametric tests is based on different reasons. In fact, a non-parametric procedure does not make strong assumptions on the distribution of the data (Hatch and Lazaraton, 1991). Moreover, non-parametric tests may be more appropriate to relatively small populations or to populations where sampling does not seem to be normal. Given that the participants who took part in this study were chosen on convenience, it would be more appropriate to use the non-parametric tests in order to offer reliable results. The two chosen tests are the Wilcloxon Rank-Sum which is the non-parametric version of the parametric T-test and the Krustal Wallis test which is the non-parametric version of the parametric ANOVA (Hatch and Lazaraton, 1991).

\section{Percentiles}

The LASSI yields ten individual scale scores, one for each of the ten scales. These scale scores can be compared numerically or graphically to the national American norms available on page 11 of the LASSI booklet. The national 
norms are marked at the $75^{\text {th }}$ and $50^{\text {th }}$ percentile to show which scale needs improvement and which does not. A percentile indicates the portion of a national American sample of students who scored at or below a particular score. Percentiles can also be used as a chart to interpret scores of the participants on the different scales of the LASSI. Students who score above the 75 percentile do not need to work on the skills included under that scale. In contrast, a student who scores between the 75 and 50 percentile should consider improving the relevant study skill in question. Finally, students who score below the 50 percentile need an urgent intervention to foster that scale.

\section{Qualitative analysis}

The qualitative analysis was applied mainly on the data retrieved from the interviews and diaries. Being a 'content analysis', this type of analysis is used to obtain more spontaneous information from the subjects (Patton, 1987) to further check the accuracy of the results obtained from the numerically based procedures.

The methodology followed in this research can be criticized on many different levels. First, the small number of participants who took part in the interviews kept diaries does not allow for wide-range generalizations. Second, the use of non-parametric tests is less-powerful than the use of the parametric ones; a fact which would make findings limited to the population studied and less subject to generalizations. Third, the timing of the data collection was critical. Indeed, administering the LASSI was so close to the period of final exams. This may have affected the students' responses, as these students may already be anxious about the approaching final exams. Finally, the fact that Saudi participants did not provide any diaries may affect the results of the findings with regard to the relationship between study skills and students' origin.

\section{Results and Discussion}

\section{Study Skills of American and Saudi Students}

To elicit the presence of any differences and/or similarities in the study skills of American and Saudi students, scores on the LASSI were coded and fed into the computer. Then, statistical analyses were run using the Statistical Package for the Social Sciences (SPSS) 10.0 for Windows. Scores were organized according to the respondents' origin as the independent variables and the LASSI scores as the dependent variables. The Wilcloxon Rank-Sum was afterwards used to calculate the significance of the scores of American and Saudi subjects on the LASSI.

Based on the $\mathrm{p}$ Value ( $\mathrm{p} \geq 0.05)$, findings that Americans and Saudi students scored differently on 7 scales which are ANX, ATT, CON, INP, MOT, SMI and TST. However, they did not score differently on SFT, STA and TMT.

Table 2. The Wilcloxon Rank-Sum test of American and Saudi students'scores on the LASSI

\begin{tabular}{l|l|l|l|l|l|l|l|l}
\hline & ANX & ATT & CON & INP & MOT & SFT & SMI & STA \\
\hline Chi-square & 3.805 & .297 & 5.031 & .673 & .309 & 2.310 & 12.637 & 1.587 \\
\hline Asymp. Sig. & .000 & .000 & .000 & .000 & .000 &. $\mathbf{1 2 9}$ & .000 &. $\mathbf{2 0 8}$ \\
\hline
\end{tabular}

The scales on which Saudi and American students answered in more or less the same way were the SFT, the STA and the TMT. These scales are supposed to measure how the students manage, regulate the whole learning process through using their time effectively, focusing their attention, meeting the learning demands for a class, an assignment or a test, and using study support such as review sessions, tutors or special features of the book (Palmer and Weinstein, 2002). Interestingly enough, both Saudis' and Americans' scores on these scales were low, making them, areas of relative weaknesses which need external remediation. For example, 57.5\% of American students scored below the $50^{\text {th }}$ percentile on the SFT and $64.1 \%$ of Saudi students have scored in the same way. Table 3 summarizes the scores of Saudi and American students on SFT, STA and TMT.

Table 3. Scores of Saudi and American Students below the $50^{\text {th }}$ percentile

\begin{tabular}{l|c|c}
\hline & $\begin{array}{c}\text { SAUDI STUDENTS } \\
\%\end{array}$ & $\begin{array}{c}\text { AMERICAN } \\
\text { STUDENTS } \\
\%\end{array}$ \\
\hline Self-testing & 64.1 & 57.5 \\
\hline Study Aids & 49.9 & 45 \\
\hline Time-management & 49.3 & 38.7 \\
\hline
\end{tabular}


Scoring low on the SFT scale was also reflected in both Saudi students' and American students' responses on the interview concerning the question about having a systematic approach to studying. 81\% of Saudi students and $73 \%$ of American students linked their approach to studying to the different nature of studying and testing set by the different types of courses, this same cause was associated with their inability to manage their time adequately. $78 \%$ of Saudi students and 56\% of American students did not study on a daily basis. Some of them, however, mainly Americans, made study schedules but found difficulties in sticking to them because of their other responsibilities like work and extracurricular activities as they explained in their diaries.

\section{Study Skills of Saudi Students}

The study skills of Saudi students who took part in this research project seemed to be weak. The following table (table 4) shows that all of the scores of Saudi students on the LASSI fall under the $50^{\text {th }}$ percentile.

Table 4. Scores of Saudi students on the LASSI below the $50^{\text {th }}$ percentile

\begin{tabular}{l|c|c}
\hline LASSI SCALE & $\begin{array}{c}\text { NUMBER } \\
\text { OF }\end{array}$ & PERCENTILE \\
1- Attitude & $\begin{array}{c}\text { OF } \\
(\mathbf{n = 1 5 6 )}\end{array}$ \\
2- Motivation & 132 & 84.6 \\
3- Anxiety & 129 & 82.6 \\
4- Test Strategies & 112 & 71.1 \\
5- Concentration & 98 & 62.8 \\
6- Selecting main idea & 95 & 60.8 \\
7- Information processing & 79 & 50.6 \\
\hline
\end{tabular}

The three most problematic study skills areas are obviously affective. More than $70 \%$ of the Saudi students scored low on the ATT, MOT and ANX scales. Saudi students seem to struggle with maintaining a positive attitude towards studying. $84.6 \%$ of them seemed to be uninterested in studying at the university and also their academic success. They did not have clear educational goals and did not think that their studies will entitle them to obtain the job they were looking for $(90 \%)$. This strong negative attitude was reflected in their lack of motivation to study. $82.6 \%$ of Saudi students had motivational issues. For example, they did not keep studying when they had low grades on exams. They also often attributed their low exam results to factors like bad luck, poor teachers, limited intelligence, or to family problems rather than to their own efforts or lack of study skills' use. This combination of negative attitudes and low motivation would eventually result in a debilitating anxiety related to their performance in general and especially during exams. It was not, then, a surprise that $71.1 \%$ of Saudi students felt anxious and tense while taking exams and thus failed to answer to the best of their knowledge.

Saudi students need an urgent intervention in repairing their affective relationship with university. Such a negative relationship resulted in a major problem pertaining to the cognitive skills involved while studying. For example, $62.8 \%$ of Saudi students scored on the TST scale below the $50^{\text {th }}$ percentile and $50.6 \%$ of them scored below the $50^{\text {th }}$ percentile on the SMI scale. These low percentages suggest the presence of an alarming situation where Saudi students seem to be unable to deal with the amount of information they are receiving.

In summary, Saudi students seem to be:

- unable to select main ideas appropriately and to process the information effectively.

- unable to relate what they are studying to their future professional life,

- very anxious while taking exams,

- easily distracted while studying.

\section{Study Skills of American Students}

The study skills of the 80 American students who took part in this study could be evaluated as weak to moderate. The following table (table 5) presents the classification of scores of American students on the LASSI below the $50^{\text {th }}$ percentile.

The two affective scales of ATT and MOT constituted areas of relative weaknesses for American students. 57.5\% of 
them scored below the $50^{\text {th }}$ percentile on the ATT scale the fact which implied that American students did not have higher level goals behind studying and that they did not consider studying as relevant to their life goals.

Table 5. Scores of American students on the LASSI below the $50^{\text {th }}$ percentile

\begin{tabular}{l|l|l}
\hline LASSI SCALE & $\begin{array}{c}\text { NUMBER OF } \\
\text { STUDENTS } \\
(\mathbf{n}=\mathbf{8 0})\end{array}$ & $\begin{array}{l}\text { PERCENTILE } \\
\%\end{array}$ \\
\hline 1- Attitude & 46 & 57.5 \\
2- Self-testing & 46 & 57.5 \\
3- Motivation & 37 & 46.2 \\
4- Concentration & 35 & 43.7 \\
5- Anxiety & 28 & 35 \\
6- Information processing & 25 & 31.2 \\
7- Selecting main idea & 21 & 26.2 \\
\hline
\end{tabular}

Among the American participants, $46.2 \%$ scored below the $50^{\text {th }}$ percentile on the Motivation scale. In the interview, they justified their absence of motivation to work on a daily basis, for example, by the large amount of work they had to do in class as well as to the number of their extracurricular activities and their work commitments. Indeed, $75 \%$ of them had part time jobs parallel to their studying. Nevertheless, American students' scores on the cognitive scales present areas of relative strengths rather than weaknesses.

Indeed, only $23.7 \%$ reported test-taking and preparing difficulties. They seemed to be familiar with the characteristics of the different types of tests and how to answer them. According to Weinstein and Palmer (2002), knowing how to take tests helps the students "target their study activities, set up useful study goals, implement an effective study plan, and demonstrate their knowledge" (p.13). This was indeed reflected in their low scores on the Anxiety scale. Additionally, both the cognitive skills of information processing and selection of main ideas could be considered as areas of strengths.

In a nutshell, American students seem to:

- be successful exam takers,

- have a negative attitude towards their studies

- lack the motivation to study at university

- $\quad$ possess appropriate information processing techniques.

\section{A Comparison of the Study Skills of American and Saudi Students}

The comparison of the study skills of American and Saudi students revealed that the two groups had different study skills except for SFT, TMT, and STA.

On the motivation scale, Saudi students seemed to have more difficulties with Attitude and Motivation than American students (figure 1). For example, the means of the scores of Saudi students on the MOT scale is 28 whereas for Americans it is 32. As for ANX scale, it seemed to dominate the university life of both Saudi and American since both groups fall under the $50^{\text {th }}$ percentile on the national norm. Problems with motivation were also noted during the interview since most students did not hide their lack of motivation when it came to approaching their study tasks because they usually could not connect what they were studying to their future life goals. 


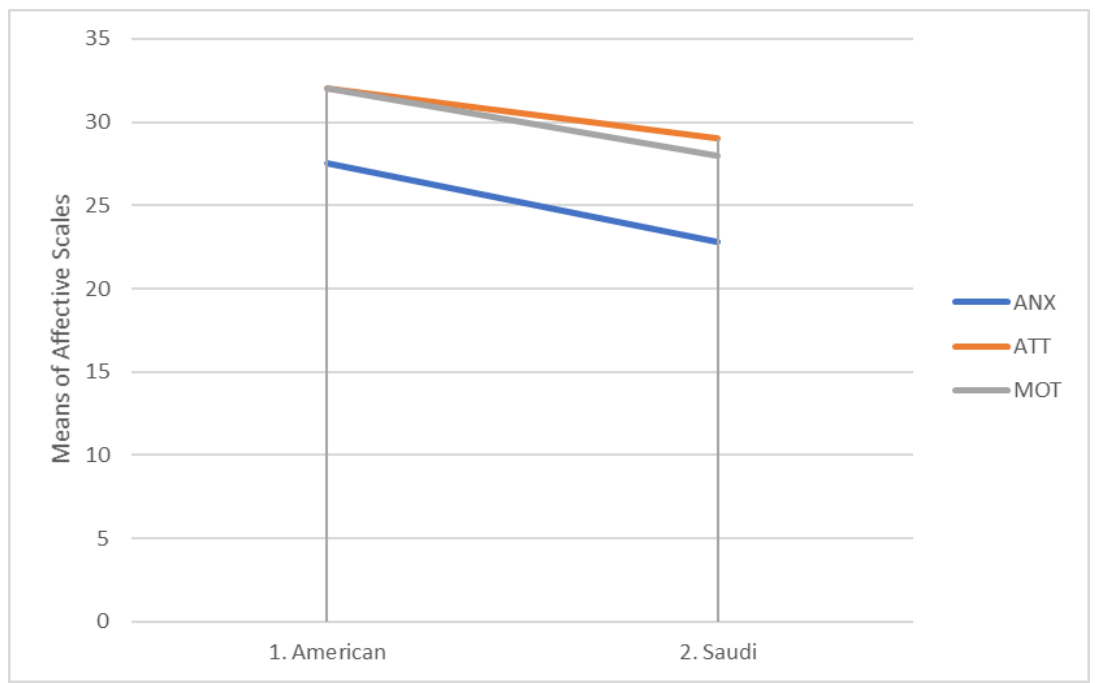

Figure1. Means of the scores of American and Saudi students on the ANX, ATT and MOT scales

On the cognitive scales, however, Saudi and American students scored significantly different (figure 2). The SMA and INP scales, for example, were very weak areas of study skills for Saudi students whereas for American students, they could be relatively considered as strong areas of study skills. This difference could be linked to the difference in the educational systems in Saudi Arabia and the USA. The latter was more related to heavy readings and intensive summary reports as well as daily testing and the second being usually based on attending lectures and final semestrial exams.

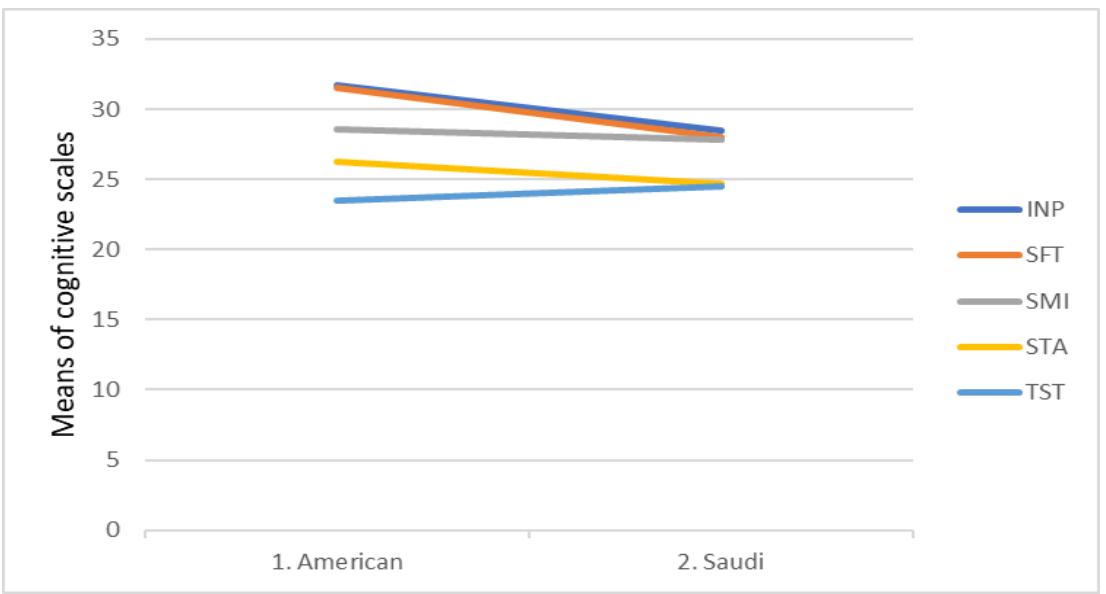

Figure 2. Scores of American and Saudi students on the cognitive scales of the LASSI

The cross-cultural comparison of study skills of American and Saudi students in this research lends strong support to previous studies in which researchers like Vesta and Moreno (1991), Tan and Goh (1999), Berberoglu and Hei (2003) agreed that study skills were affected by culture. In fact, the way students study is a reflection of a cultural background characterized by different lifestyles, languages, educational and university backgrounds (Berberoglu and Hei, 2003). The same conclusion was reached by Alrebai (2018) who maintained that culture, among other factors such as religion and society influence the "process and progress" of Saudi learners.

\section{Recommendations}

Based on the claim that study skills and learning strategies are among the main factors that determine how and howwell learners are doing in a certain subject; more researches need to be carried out in different educational settings in order to identify the different strategies and skills used by each category of students and therefore make them aware of the power of consciously and intentionally employing them in making learning faster and more effective (Nyikos \& Oxford, 1993). It is recommended, in this respect, that teachers assist their students in developing an awareness of the importance of the different study skills and strategies and their positive impact on learning. They can also help 
them select from the wide range of the study skills and the strategies that suit their abilities and needs. Therefore, learners are expected to learn these strategies as part of the curriculum. Therefore, the need to incorporate such strategies in education is urgent.

The possibility of the presence of a significant correlation between study skills and learning strategies use on one hand and the positive learning outcomes on the other is another variable to be considered for future research. However, the development of such skills by the students should not be the only focus, still the classroom practices and the teaching methods used by the teachers are to be considered and further researched so as a clearer understanding of the teaching/ learning process is drawn.

The same idea was advocated by Trigwell and Prosser (2004) who reported that the teachers' approaches to teaching are strongly associated with and affected by their students' approaches to learning. The investigation of this association would be an important direction for future research.

Furthermore, it has been indicated that students differ in learning styles and preferences, and that learning is basically individual, which "implies that standardized materials, instruction, and practices may actually diminish or inhibit learning" (Lawson, 1994, p. 2). This justifies the call to place more emphasis on the learner's learning styles and preferences if better proficiency levels are to be achieved. Thus, in addition to the study skills, learning strategies and the teaching methods, learners' preferences need to be taken into consideration to achieve better academic results. To quote Al Maghraby and Alshami (2013), "if the faculties use appropriate teaching methods which match the students' learning preferences, learning is efficient in a harmonious environment" (p.193).

\section{Conclusion}

Study skills and learning strategies are concerned with the internal cognitive and affective processes involved in studying. The present study has focused on the relationship between study skills and learning strategies on one hand and on cultural origin on the other. The investigation of the different aspects of these elements has led to the result that the culture and origin of the student was found to be influential when it came to study skills since both American and Saudi students showed different patterns of studying and learning approaches. This finding leads to the conclusion that study skills are indeed culturally affected.

More interestingly, this study revealed areas of strengths and weaknesses of study skills among university students having two different cultures. The first one is about Saudi students who have serious affective problems, especially those related to motivation and attitude and the second one is about Americans who have strong cognitive skills.

The contributions already provided, however, do not minimize the limitations which could be said to exist in this comparative study in particular and in comparative studies in general. Indeed, investigations of the study skills of college students have employed a variety of measurement instruments and methodologies, making comparisons across studies somehow problematic.

Another limitation which can be stated concerns the use of the LASSI. In fact, LASSI scores are based on the American studies and represent American norms. This may have favored the American participants. Norms for the Saudi context have not been calculated. The results could have been more objective if independent norms for the Saudi context have been made by choosing a representative sample of Saudi students from different universities and regions.

Last but not least, thanks to the conclusion this study has made about the culture specificity of study skills, teachers and curriculum designers should be critical when adopting teaching strategies which have worked in contexts different from the Saudi one. For, teaching study skills should be in context, that is, by identifying the social as well as the academic requirements of a particular situation and equipping students to cope with them. The culture specificity of study skills should also be taken into consideration while dealing with international students who may be used to study situations and methods different from the Saudi ones.

This study can be considered as conventional in the sense that it has focused on students in a face-to-face situation. Further exploration should be done in the area of distance learning. Finally, the differences in study skills between American and Saudi students should be the basis for more research exploring the environmental and contextual factors that influence the development and use of study skills in these settings and others.

The students' study skills and approaches to learning may not match the requirements they are supposed to fulfill in overseas educational settings. What is positive is that such patterns of learning are not rigid but flexible and may change according to the students' new situations as learners abroad. However, the pace with which such change and the adoption of new skills may happen can be slow which may engender frictions between the beliefs these students 
bring along and the study skills they are actually requested to develop in order to make their learning a successful experience. If surrounded by professional staff that acknowledge the influence of culture on the choice of one's particular study skills or learning approaches and thus pay more attention to cultural diversity between students, the latter will live a balanced study experience that would add to their education abroad and to their lives in general.

\section{References}

Al Maghraby, M., \& Alshami, A. M. (2013). Learning style and teaching method preferences of Saudi students of physical therapy. Medical Education, 20(3), 192-197. https://doi.org/10.4103/2230-8229.122017

Albaili, M. A. (1997). Differences among low-, average- and high-achieving college students on learning and study strategies. Educational Psychology, 17(12), 171-177. https://doi.org/10.1080/0144341970170112

Al-hillawani, Y., \& Sartawi, A. (1997). Study skills and habits of female university students. The College Student Journal, 31(4), 567-576.

Alrabai, F. (2018). Learning English in Saudi Arabia. https://doi.org/10.4324/9781315688466-5

Berberoglu, G., \& Hei, L. M. (2003). A Comparison of University Students' Approaches to Learning across Taiwan and Turkey. International Journal of Testing, 3(2), 173-187. https://doi.org/10.1207/S15327574IJT0302_6

Bliss, L., \& Mueller, R. (1993). An instrument for the assessment of study behaviors of college students. Reading Research and Instruction, 32(4), 46-52. https://doi.org/10.1080/19388079309558132

Communicative Classroom. Boston: Heinle \& Heinle.

Cottrell, S. (2001). Teaching study skills and supporting learning. Basingstoke, Palgrave Macmillan. https://doi.org/10.1007/978-1-137-07094-4

Haynes, N. (1993). Critical issues in educating African-American children. Langley Park, MD.; IAAS Publishers, Inc.

Hofstede, G. H. (2001). Culture's consequences: Comparing values, behaviors, institutions, and organizations across nations (2nd ed). California: Sage Publications.

Kember, D., \& Gow, L. (1990). Cultural specificity of approaches to study. British Journal of Educational Psychology, 60, 356-363. https://doi.org/10.1111/j.2044-8279.1990.tb00952.x

Kizlik, B. D. (2011). Effective Study Skills. Retrieved from http://www.adprima.com/studyout.htm

Lawson, J. (1994). Brain-Based Learning. Retrieved from https://www.jstor.org/stable/43766960

Lee, W. O. (2008). The repositioning of high education from its expanded visions: Lifelong learning, entrepreneurship, internationalization and integration. Educational Research for Policy and Practice, 7, 73-82. https://doi.org/10.1007/s10671-008-9045-2

Marambe, K. N., Vermunt, J. D., \& Boshuizen, H. P. (2012). A Cross-Cultural Comparison of Student Learning Patterns in Higher Education. High Educ, 64, 299-316. https://doi.org/10.1007/s10734-011-9494-z

Mutsotso, S. N., \& Abenga, E. S. B. (2010). Study methods for improving quality learning and performance in Higher Education. Educational Research and Review, 5(12), 808-813.

Oxford, R. L. (1990). Language Learning Strategies: What Every Teacher Should Know. Boston: Heinle \& Heinle.

Proctor, B. K., Adams., A., Hurst., F., Prevatt, F., \& Petscher, Y. (2006). Study skills of normal-achieving and academically college struggling college Students. Journal of College Student Development, 41(1), 37-51. https://doi.org/10.1353/csd.2006.0011

Scarcella, R., \& Oxford, R. (1992). The Tapestry of Language Learning: The Individual in the

Steele, M. M. (2010). High school students with learning disabilities: Mathematics instruction, study skills and high stakes tests. American Secondary Education, 38(3), 21-27.

Tan, J., \& Goh, J. (1999). Assessing Cross-Cultural Variations in Student Study Approaches: an ethnographic approach. In K. Martin, N. Stanley, \& N. Davison. (Eds). Teaching in the Disciplines: learning in content. (pp. 409-416). Procedure of the $8^{\text {th }}$ Annual Teaching Learning Forum, the University of Western Australia. Retrieved from http:// lsn.curtin.edu.au/tlf/tlf2000/Williams.html

Trigwell, K., \& Prosser, M. (2004). Development and use of the approaches to teaching inventory. Educational Psychology Review, 16, 409-424. https://doi.org/10.1007/s10648-004-0007-9 
Vermunt, J. D. (1998). The regulation of constructive learning processes. British Journal of Educational Psychology, 68, 149-171. https://doi.org/10.1111/j.2044-8279.1998.tb01281.x

Vermunt, J. D. (2007). The power of learning environments to influence student learning. British Journal of Educational Psychology Monograph Series II, 4, 73-90.

Vesta, F., \& Moreno, V. (1991). Cross-cultural Comparisons of Study Habits. Journal of College Student, 30(3), 329-336.

Weinstein, C. E. (1987). Learning and Study and Strategies Inventory (LASSI) user's manual. Clearwater, FL: H\&H Publishing.

Weinstein, C. E., \& Palmer, D. R. (2002). Learning and Study Strategies Inventory (LASSI): user's manual (2 ${ }^{\text {nd }}$ Ed,). Clearwater, FL: H \& H Publishing. 